\title{
Mother-Daughter Intergenerational Influence on Clothing Products: Cultural Perspectives
}

\author{
Abdelhalim I. Al-Zu'bi \\ Business school, Marketing Department, Al-Balqa' Applied University, Al-Salt, Jordan
}

\begin{abstract}
Research in consumer socialization behavior has overlooked mother-daughter intergenerational influence within the context of Arab culture. Based on 57 mothers/daughters dyads responses, this study aims to identify the similarity/dissimilarity attitudes between Jordanian mothers and their young daughters (age: 18-24) towards marketplace activities and marketing practices concerning clothing product. It also tends to measure the relative influences of mothers' beliefs in marketplace activities and marketing practices on their daughters. The principal component factor analysis and confirmatory factor analysis were used to validate the research model. Paired sample ttest and multiple regression analysis using Structural Equation Modeling were employed to examine the research hypotheses. Results revealed that the best predictors of the general attitudes of daughters towards marketplace activities and marketing practices were respectively accounted for mothers' attitude towards purchasing clothing items on sale, clothing stores preferences, and TV advertising values. Some of the managerial implications, limitations, and suggestions for future research were also discussed.
\end{abstract}

Key Words: Jordan, young consumers, intergenerational influence, marketing practices, consumer socialization behavior, collectivist culture, structural equation modeling

\section{Introduction}

Socialization is a life-long process that enables people to learn the society role and regulations (Brim, 1968) which in turn affect individuals' consumption behaviors through their life stages (Calder et al., 1975; Moore et al., 2002; Moschis, 2007). In contrast, consumer socialization refers to "the process by which young people acquire skills, knowledge, and attitudes relevant to their functioning as consumers in the marketplace" (Ward 1974, p. 2) as a result of parent-child interaction process (Moschis, 1987). Hence, previous research has viewed parents as the most powerful consumer socialization agent because they serve as a model for their children, a source of information, and an instrument of norms and values (e.g., Childers \& Rao, 1992; LaChance et. al, 2003; Maccoby, 2007; Mittal \& Royne, 2010; Shobri et al., 2012; Ward, 1974). In 1979, Berger and Berger distinguished between primary and secondary socialization processes. Primary socialization takes place during the childhood stage while the secondary socialization echoes the adulthood period (Berger \& Berger, 1979), for instance, the clothing code depends on secondary socialization (Watne et al., 2011) and provides information to others (Kefgen \& Touchie-
Specht, 1986). Danesi (2004, p. 179) defines clothing as "signs extending the basic meaning of bodies in a cultural context" that conveys symbolic meanings and cultural orientations (Hirschman \& Holbrook, 1982). Therefore, product attributes should match the cultural values of consumers (Burgess \& DrakeBridges, 2010). Clothing is an essential product for all consumers (Holman, 1980; Mittal \& Royne, 2010), characterized by its high visibility to others (Heckler et al., 1989), and reflected an individual's personality and social identity (Chattalas \& Harper, 2007). The family members are more likely to influence privately consumed goods while the influence of other reference groups is stronger for publicly and luxury consumed goods (Bearden \& Etzel, 1982). Additionally, Miller (1975, p. 93) states "Are the general patterns of consumption behavior which are

Corresponding author: Abdelhalim I. Al-Zu'bi, PhD, Business School, Marketing Department, Al-Balqa' Applied niversity, Al-Salt, Jordan, E-mail: rabdoissazoubi@yahoo.com

\footnotetext{
(c) This article is distributed under the terms of the Creative Commons Attribution License, which permits unrestricted use and redistribution provided that the original author and source are credited.
} 
observed by children in the parental home reflected in similar behavior by these children after they become adults? To what degree are broad value orientations that impinge on consumer behavior passed on between parents and children?" However, the underlying themes of these questions were later used to validate the notion of intergenerational influence "IGI". IGI refers to the transmission of parents' consumption beliefs, attitudes, and preferences to their children (Moore-Shay \& Lutz, 1988; Moore et al., 2002; Moschis, 1988; Viswanathan et al., 2000) including consumption knowledge, values, and continuation of traditions (Heckler et al., 1989; Shah \& Mittal, 1997). Mothers and daughters manifest analogous attitudes towards brand preferences, prestige sensitivity, convenience products, and price-quality relationship (Mandrik et al., 2005). Daughter of ages 18-22 trusted their mother in gaining the skills of shopping as part of the maternal nurturing and training roles (Minahan \& Huddleston, 2010). In the assessment of intergenerational influences on consumption behavior, Viswanathan et al.'s (2000) study revealed that IGI encompasses consumption preferences of products, brands and stores selections, consumer skills, and marketplace attitudes. Further, previous research stressed the importance of investigation IGI on consumer research. For instance, the intergenerational influence on consumer behavior within generation from the older (parent) to the younger generation (children), is an interesting question that should receive a great deal of attention within consumer research (Wilkie 1986, p.181). Also, Mittal and Royne (2010) state "It would be of interest to investigate the role of family relationship quality FRQ in families in collectivist cultures, ....In collectivist cultures, IGI might be present to an even greater degree among all families" (p. 253). However, IGI research has examined a wide spectrum of topics including decision making (Childers \& Rao, 1992; Opoku, 2012; Perez et al., 2011), value transmission (Mittal \& Royne, 2010; Whitbeck \& Gecas, 1988), consumer innovativeness (Cotte \& Wood, 2004), brand preferences and loyalty (Moore-Shay \& Lutz, 1988; Shobri et al., 2012). Departing from these arguments, the objectives of the present study are as follows:

-Investigate the similarity/dissimilarity attitudes among Jordanian mothers and young adult daughters towards marketplace activities "clothing brand selection, stores preferences, and propensity to purchase clothing items on sale", marketing practices "TV advertising values and TV advertisements oriented children", and accepting the authority of males' consumer roles. In 2013, young consumers in Jordan had formed 21.5\% of the population (Khraim, 2015). Mothers play a crucial role in teaching their children the consumer skills because they co-shop more frequently with daughters than sons (e.g., Roberts et al., 1981; Neeley, 2005). The transmission of consumption practices between mothers and daughters is considered as part of the consumer's day-to-day life (Ladwein et al., 2009). Thus, the effect of IGI on consumer behavior based on specific dyads responses such as mother-daughter is an interesting topic to explore (Cotte \& Wood, 2004; Mittal \& Royne, 2010; Moore-Shay \& Berchmans, 1996; Moschis, 1988; Wilkie, 1986).

- Measure the relative impacts of mothers' attitudes towards marketplace activities, marketing practices, and mothers accepting the authority of males' consumer roles on the general attitudes of their young adult daughters related to clothing product. The home environment may either facilitate or hamper the transmission of beliefs and attitudes from parent to children (Mandrik et al., 2005; Moore-Shay and Berchmans, 1996), and the culture orientations tremendously influence parents' roles (e.g., Haq \& Rahman, 2015; Ward et al., 1987).

To explore these objectives insightfully, the structure of the paper will firstly introduce the related literature to formulate the main hypothesis to be tested, secondly, describe the methodology, third, report the findings and discussion, and finally, presents the managerial implications, limitations, and future research.

\section{Literature Review and hypotheses}

\section{Intergenerational influence and consumer sociali- zation}

The marketing literature has demonstrated that the IGI influence overwhelmingly relies on consumer socialization theory and Newcomb's coorientational paradigm (1953, p. 393). In that, parents via IGI reshape their children's values, attitudes, and behaviors in different situations owing that to the vital roles of parents in developing the consumer role of their children (e.g., Heckler et al., 1989; Mandrik et al., 2005; Moore et al., 2002; Moschis, 2007). The transfer of perceptions and skills of shopping is bi-directional. Daughters share brand knowledge with their mothers, and the strength of the maternal influence seems to continue throughout the daughter's life (Minahan \& Huddleston, 2010). As a result, the more likely children perceive parents' socialization values accurately, the more children's personal values match parents' socialization values (Whitbeck \& Grecas, 1988). Earlier, Arndt (1972) found that the family members have exhibited the similar tendencies towards favorite stores and brand loyalty that differed across product categories (Childers \& Rao, 1992; 
Mittal \& Royne, 2010; Siddiqui et al., 2012). In Pakistan, the intergenerational influence on the brand preferences related to durable products is higher than IGI on the convenience goods (Siddiqui et al., 2012) whereas IGI on the brand preferences of American students under the age of 30 has stronger effects on convenience goods more than shopping goods (Heckler et al., 1989). Furthermore, the similarity between daughter's and mother's attitudes towards apparel, shopping at used clothing stores, and department stores were observed (Francis \& Burns, 1992). Thus, the most consequences of parent influence on children's behavior are obviously related to price consciousness and sensitivity, information search behavior, store and brand loyalties, and responses to advertising and promotion (Childers \& Rao, 1992; Viswanathan et al., 2000). Regarding the power of IGI explanations, parents influenced their children by $53 \%$ while $38 \%$ of influences emanated from peer inputs (Cheliotis, 2010). The store patronage of tweens as a sub-group of Generation $\mathrm{Y}$ is not associated with the friends' opinions, and $50 \%$ of parents helped them in clothing purchase decisions compared to $13 \%$ of friends' opinions (Burgess \& Drake-Bridges, 2010). The intergenerational agreement between mother/daughter dyads for brand preference is estimated by $43 \%$ for low-visibility products and $57 \%$ for highvisibility products whilst mothers and daughter failure to predict one another's with respect to buying items on sales, willing to try new brands, and brand loyalty. Therefore, the stronger IG impacts are associated with in-home visibility products (Moore-Shay \& Lutz, 1988).

Regarding family communication structures, the outcomes of socialization depend on the quality of parent-child relations (Moore et al., 2002; Mittal \& Royne, 2010). The strength of family relationship refers to the harmony of relations between parents and their children in every aspect of life (Moschis, 1988) which in turn influences parents and young adults purchase behavior (Webster \& Wright, 1999). The frequency of parent-child interaction and emotional closeness significantly adjust the attitudes and the monetary values of young adults (Moore-Shay \& Berchmans, 1996), and is positively related to the intergenerational agreement between mothers and daughters. That is, daughters' college students predict $45 \%$ of mothers' brand preferences compared to mothers' prediction $27 \%$ of their daughter's preferences (Mandrik et al., 2005). Based on the framework of brand equity, parents intergenerational conversation and recommendation were positively influenced the brand association, and the brand quality of Chinese young adult ages ranged from 18 to 27 . The positive influence on intergenerational perceived quality and intergenerational brand loyalty was not significantly supported (Cai et al., 2015). Moreover, intergenerational influence is not strong enough among families of low-quality relationship, and parent influence is evident on offspring choice of products, brands, and stores (Mittal \& Royne, 2010). Based on parents and young adults dyadic responses to validate the scales of intergenerational communication influence, the linkage between the influence of intergenerational communication and the age of respondents was found; the correlation coefficient in Thai's sample is higher than American's sample (Viswanathan et al., 2000). Dependent on the above debates, the two first hypotheses can be formulated as follows:

H1: Mothers and young daughters do not manifest similar attitudes towards (a) purchasing clothing items on sale, (b) clothing store preferences, and (c) clothing brand preferences.

H2: Mothers' attitudes towards (a) purchasing clothing items on sale, (b) clothing store preferences, and (c) clothing brand preferences do not influence daughters' general attitudes towards marketplace activities and marketing practices.

Furthermore, there is a relationship between parents and young children skepticism towards advertising resultant to IGI on TV advertising values and trustfulness. Mothers do not trust TV advertising (Moore-Shay \& Lutz, 1988) hence parents skeptical towards advertising negatively influence children susceptibility to advertisements (Obermiller \& Spangenburg, 2000). Within the context of normative and informational influences, Opoku (2012) found that the purchase decisions of Saudi's young adults are more influenced by the normative influences "appearance and social status" than informational influences, in that, Asian American youth relies on mass media as a source of information (Moschis, 1987). Shobri et al. (2012) examine the influences of family, peers and television advertisement on the fast food brand loyalty. The brand loyalty of Malaysian adults aged from 19 to 41 is more likely to be influenced by television advertisements more than the family influences. Haq and Rahman (2015) confirmed the positive influence of reality television on the teenage consumers' socialization, consumption-related cognition, attitudes, and values. Teenagers' involvement in television and consumer-socialization process is significantly affected by parental control, peer-group influences, gender, and social class differences. In contrast, Asian American, Hispanic, and African American young adults considered informative peer influences as major socialization agents compared with parental normative and media normative (Singh et al., 2003). These findings, however, lead to propose the following hypotheses: 
H3: Mothers and young daughters do not demonstrate similar attitudes towards (a) TV advertising values and (b) children's commercial advertisements.

H4: Mothers' attitudes towards (a) TV advertising values and (b) children's commercial advertisements do not affect daughters' attitude towards marketplace activities and marketing practices.

\section{Cultural dimensions and intergenerational influence}

National culture is "a set of understandings shared among persons who have been similarly socialized" (Yates \& Cutler, 1996, p. 78) hence the family is the major agency for cultural transmission (Ward, 1974). However, a number of academic researchers emphasize the importance of investigating parent-child interaction process in different cultures to expand the theoretical framework and practical literature on consumer socialization behavior (Mittal \& Royne, 2010; Perez et al., 2011; Maheswaran \& Shavitt, 2000; Ward et al., 1987). According to Hofstede's (1980, p. 19) cultural dimensions theory, culture refers to "the interactive aggregate of common characteristics that influences a group's response to its environment". Apparently, culture influences determine how groups interact and react to the different environment, in that, the most conservative mothers, the young children would exert less influence on family decision making (Roberts et al., 1981). Hofstede (1980) proposed four cultural dimensions including individualism-collectivism, uncertainty avoidance, power distance, and masculinity-femininity. Specifically, the groups of individualistic cultures stress the emotional independence, self-reliance, assert the individual rights, personal goals, and choose their affiliations groups. By contrast, individuals of collectivist society stressed in-group goals over their personal interests, encouraged interdependence, mutual esteem, respect, and gave more weight to the society norms in comparison with individualistic groups (Triandis, 1995; Yamaguchi et al., 1995). The dimension of power distance refers to which extent the less powerful members of a given society accept and expect the unequal relations with high powerful members (Mooij \& Hofstede, 2010), on that basis, the Asian cultures scored the highest grades on the index of power distance (Hofstede, 1983). In the feminine culture, household work is more likely to be shared by the husband and wife than in masculine cultures (Mooij \& Hofstede, 2010). In a society with patriarchal family norms, a man has legitimate authority within his family by virtue of his maleness...The low-income man does not therefore suffer any loss of authority (Rodman 1972, p. 67). Equally, the individuals of vertical collectivism accept the inequality roles of their group members whereas individuals of horizontal collectivism perceive themselves as part of their affiliation groups but stress equality since they perceive all members of the group as the same (Singelis et al., 1995; Triandis \& Gelfand, 1998). Additionally, individuals of Arab societies display tremendous loyalty to their affiliated groups, and the yielding levels are measured through respecting parents' requests and orders (Shoup, 2007). Consequent$1 \mathrm{y}$, the intergenerational influence is stronger in the collectivistic society when it is compared to the individualistic society because young consumers reside and remain in closer contact with their parents for a long period (Perez et al., 2011). In that, susceptibility to peers, parents, and media is significantly varied among Hispanic and African American young adults (Singh et al., 2003). The intergenerational influence on private products "luxuries and necessities" is higher in the Thailand sample than the American sample (Childers \& Rao, 1992).

However, the above arguments lead to suggest the following hypotheses:

H5: Mothers and young daughters do not display similar attitudes towards accepting the authority of male consumer role.

H6: Mothers' attitudes towards accepting the authority of male consumer roles do not affect daughters' attitudes towards marketplace activities and marketing practices.

\section{Methodology}

\section{Sampling and data collection}

This study used quantitative research approach. A convenience sampling technique was applied to investigate mothers IGI on the general attitudes of their daughters toward marketplace activities and marketing practices. The unmarried daughters aged from 18 to 24 and their mothers represent the unit of analysis. Specifically, 57 pairs of mother-daughter dyads responses using two identical administration surveys were separately conducted in their home/Amman metropolitan to solicit the primary data with the assistance of six graduate female students.

According to the instrument design, the two questionnaires have consisted of three sections. The first section began with mothers' socioeconomic status including age, educational level, employment sector, and mothers' yearly income whilst the second section that involving 16 items was proposed to measure the general attitudes of mothers and their young daughters towards marketing activities and marketing practices. In the third section, six items were used to measure mothers and daughters attitudes towards accepting the authority of males' consumer roles in market milieu. Mothers and daughters were 
asked to indicate their level of agreement with each item on a 5-point Likert scale (1= strongly disagree and $5=$ strongly agree). Prior data collection and to guarantee the accuracy of statements formulation, these items were translated into Arabic language and then back-translated into English. All personal interviews were completed over a period of 8 weeks in 2014 keeping in mind that the subjects were voluntary participated in this study.

\section{Measurement and validity}

In this study, the general attitudes towards marketplace activities and marketing practices (16 items) were conceptualized as to what extent mothers and their young daughters agree/disagree on using specific criteria in choosing clothes brands, clothing store preferences, propensity to purchase clothing items on sale, TV advertising values, and TV commercial advertisement oriented young consumers. Within the contextualization of collectivist cultures, accepting the authority of male's consumer role consisting of ( 6 items) was operationalized as to which extent mothers and daughters perceived that the society values, norms, and traditions empower males' consumer roles in marketplace activities. However, the survey items were initially compiled from previous research (e.g., Heckler et al., 1989; Mittal \& Royne, 2010; Moore-Shay \& Lutz, 1988; Singelis et al., 1995; Triandis \& Gelfand, 1998) to measure the dimensions of the study constructs. The principal component factor analysis-varimax rotation (PCA) and confirmatory factor analysis (CFA) were sequentially conducted to identify the latent variables of mothers and young daughters' attitudes towards clothing marketplace activities and practices.

The results of adequacy and Bartlett's test provide evidence to the fitness of the observed data to the factor analysis $\left(\mathrm{KMO}=0.61 ; \chi^{2}=352.887\right.$, df $=$ $120, \mathrm{p}=0.00)$. As shown in Table 1 , the factor analysis of the merged samples using eigenvalues greater than 1.0 with a rotated factor loading scores $\geq .50$ has yielded a five-factor solution explaining $57 \%$ of the total variance after deleting factor six (composite reliability $=.44)$. Thus, the scales that their composite reliability, according to Bagozzi and Yi's (1988) suggestions, surpassesed alpha coefficients (.60) were included in the subsequent analysis involving the construct of accepting the authority of male's consumer roles (Cronbach's alpha $=.67)$.

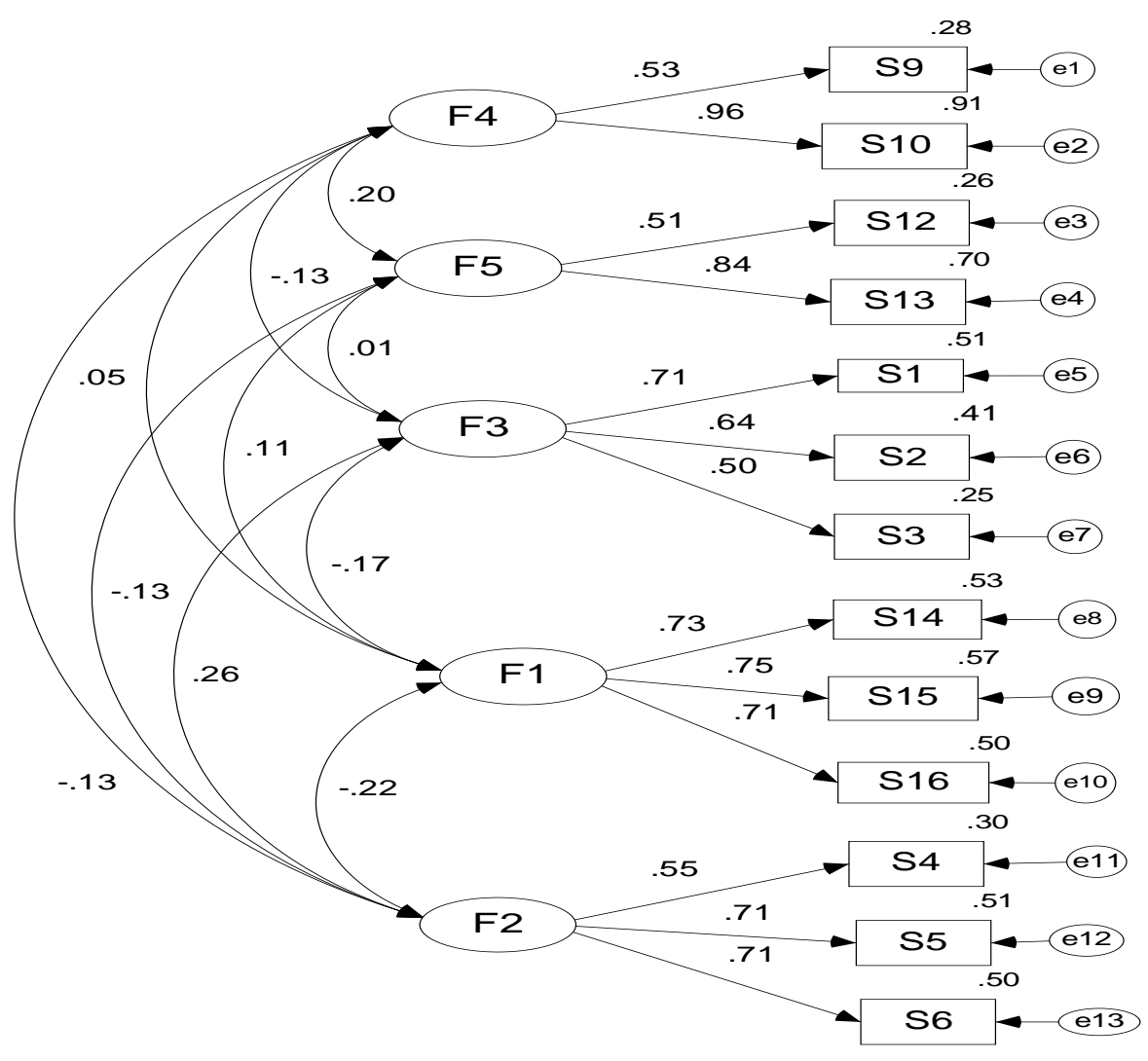

Figure.1: the confirmatory factor analysis for a five-factor solutions F: undrelying dimension; $S$ : scale items; e 1...e13: standared error of variences. 
Moreover, the results of CFA using AMOS version 7.0 (see Figure 1) support the multi-dimensionality of this construct; $\chi^{2}=72.768, \mathrm{df}=57, \mathrm{CMIN} / \mathrm{DF}=$
$1.277<3, \mathrm{GFI}=.91, \mathrm{AGFI}=.86, \mathrm{NFI}=.784, \mathrm{CFI}=$ $.94, \mathrm{TLI}=.92, \mathrm{RMSEA}=.049$.

Table 1: Principal Component Analysis for the entire samples mothers and daughters; no.114)

\begin{tabular}{lcccccc}
\hline $\begin{array}{c}\text { Factor loading } \\
\text { statistics }\end{array}$ & $\begin{array}{c}\text { TV advertis- } \\
\text { ing values }\end{array}$ & $\begin{array}{c}\text { Purchase clothing } \\
\text { items on sale }\end{array}$ & $\begin{array}{c}\text { Brands } \\
\text { selection }\end{array}$ & $\begin{array}{c}\text { Store prefer- } \\
\text { ences }\end{array}$ & $\begin{array}{c}\text { Children TV } \\
\text { advertisement }\end{array}$ & $\begin{array}{c}\text { Quality-price } \\
\text { relationship }\end{array}$ \\
\hline $\begin{array}{l}\text { Eigenvalue } \\
\% \text { of total Var- }\end{array}$ & 2.631 & 1.832 & 1.770 & 1.614 & 1.325 & 1.280 \\
$\begin{array}{l}\text { iance } \\
\begin{array}{l}\text { Composite } \\
\text { reliability }\end{array}\end{array}$ & .78 .444 & 11.447 & 11.065 & 10.088 & 8.281 & 8.000 \\
$\begin{array}{l}\text { Average Vari- } \\
\text { ance Extracted }\end{array}$ & .48 & .70 & .63 & .74 & .64 & .43 \\
\hline
\end{tabular}

According to Steiger's (1990) recommendations, RMSEA value shows a good fit to the sample data and the standardized items for each factor loadings $\geq$ (.50) secure the convergent validity (Bagozzi \& Yi, 1988). In addition, the discriminant validity was supported since the correlation coefficients between two subscales don not exceed the respective composite reliabilities ( $r=-.22$ to .26$)$.

\section{Results}

\section{Sample profile}

The market of young consumers has typically covered ages that ranged from 15 to 24 years (Lewis \& Bingham, 1991) in that the average of daughters ages is 22.5 years. Mothers ranging in age from 35 to 50 have constituted $61 \%$ of mothers sample while the remaining percentage represented mothers of 50 years old and above. Forty-six percent of mothers holds a diploma degree or less and 54\% holds a bachelor degree and above. Seventy-nine percent of mothers worked in the public sector while $21 \%$ of mothers employed in private sector. Economically, $44 \%$ of annual household income is less than US\$ 8500.00 whereas the category of annual household income ranging from US\$ 8501.00 to less than US\$ $17,000.00$ represents 30 percent of mothers' sample. About $26 \%$ of yearly household income constitutes the category of US\$17,000 and above.

\section{Descriptive analysis}

Dependent on the total scores for each dimension, Table (2) shows that daughters are more likely to wear certain brands of clothes, focus on the wellknown national brands, compare two or more brands reasonably and carefully, and purchase the clothes that give them the best overall value for their money than mothers. Mothers and daughters have nearly displayed analogous agreement (mothers $=37 \%$, daughters $=44 \%$ ) with the statement that the products on sale are always a bargain. They used to buying product that is on sale or promotion (mothers = $44 \%$, daughters $=47 \%$ ). $77 \%$ and $67 \%$ of mothers and daughters respectively prefer to shop in stores where they feel at home and believe that a nice department and specialty stores offer them the best products. Similarly, $68 \%$ and $75 \%$ of mothers and daughters respectively have an agreement with the statement "TV commercial advertising urges young children to buy things they do not really need". Eighty-Two of mothers and daughters (79\%) agree that TV commercial advertising uses tricks and gimmicks to get young children to buy their products. Further, mothers have less positive attitudes towards using the information of commercial advertising in buying decisions; $21 \%$ of mothers' responses are associated with an agreement and strongly agreement compared to daughters' responses (48\%). Daughters believe that the commercial advertising helps people to buy products that best fit their needs (agree and strongly agree $=33 \%$ ) because it tells the truth about products $(37 \%)$. In relation to accepting the authority of male consumer roles, $52 \%$ of mothers and daughters agreed that the society values, norms, and traditions restrict the female to go shopping independently while $47 \%$ and $42 \%$ of mothers and daughters agreed that buying a product, in general, is the chore of a male not that of the female. About $73 \%$ of mothers and daughters agreed that a male asks only the boy's help to buy some products for the family use" whilst $45 \%$ agreed that the male should tell only the boys where different products could be purchased compared to daughters' responses (35\%). 


\section{Testing hypotheses}

Following past research procedures (e.g., MooreShay \& Lutz, 1988; Moschis, 1988; Viswanathan et al., 2000), paired sample $t$-test was used to test the similarity/dissimilarity between mothers and daughters. As shown in Table 2, results uncover that moth- ers and daughters have displayed similar attitudes towards purchasing clothing items on sale (H1a), store preferences $(\mathrm{H} 1 \mathrm{~b})$, TV commercial advertisement oriented children (H3b), and accepting the authority of male consumer roles (H5); $t$ - values for the summated items for each subscale $\langle 2, \mathrm{P}\rangle .05$.

Table 2: Paired sample t-test of the model constructs

\begin{tabular}{lcccccc}
\hline \multicolumn{1}{c}{ Model constructs } & \multicolumn{2}{c}{ Mothers } & \multicolumn{2}{c}{ Daughters } & \multicolumn{2}{c}{ statistics } \\
\cline { 2 - 7 } & Mean & SD & Mean & SD & $t$ value & P \\
\hline Mothers attitude towards clothing brand preferences. & 12.58 & 3.251 & 15.81 & 3.686 & -21.196 & .000 \\
Propensity to purchase clothing items on sale. & 6.86 & 2.488 & 6.84 & 2.684 & .039 & .969 \\
Store preferences. & 7.28 & 1.952 & 7.74 & 1.685 & -1.235 & .19 \\
TV commercial advertisement oriented children. & 5.88 & 1.524 & 5.88 & 1.268 & 0.00 & 1.00 \\
TV advertising values. & 9.61 & 2.575 & 8.122 & 2.044 & 3.638 & .001 \\
Accepting the authority of male's consumer roles. & 20.82 & 4.123 & 20.00 & 3.937 & 1.074 & .287 \\
\hline
\end{tabular}

In opposition, mothers and daughters attitudes towards clothing brand preferences $(\mathrm{H} 1 \mathrm{c})$ and TV advertising values $(\mathrm{H} 3 \mathrm{a})$ have significantly differed; $t$ values $>2, \mathrm{P}<.05$.

Moreover, the multiple regression analysis via Structural Equation Modeling (SEM) in AMOS 7 was used to test the null hypotheses. Prior testing these hypotheses, the measures of the structural model were identified. Results indicate that the values of the fit index are within the commonly accepted standards (Hair et al., 1998); $\chi^{2}=16.5$, df $=15$, CMIN/DF $=1.098, \mathrm{P}=.35>.05, \mathrm{GFI}=.93, \mathrm{AGFI}=$ $.87, \mathrm{NFI}=.77, \mathrm{CFI}=.97, \mathrm{TLI}=.96, \mathrm{RMSEA}=.04$. As shown in Figure 2, the results suggest that the six independent variables have collectively explained $69 \%$ of the variance of daughters' attitudes towards marketplace activities and marketing practices. In that, mothers' propensity to purchase clothing items on sale $(\mathrm{H} 2 \mathrm{a})$ has positively explained the variance in daughters' attitudes towards marketplace activities and marketing practices $(\beta=.52, t$-value $=7.089, \mathrm{p}=$ $.002)$ followed by $(\mathrm{H} 2 \mathrm{~b})$ mothers store preferences $(\beta$ $=.45, \mathrm{t}$-value $=6.102, \mathrm{p}=.001)$, and $(\mathrm{H} 4 \mathrm{a})$ mothers perception of TV advertising values $(\beta=.33, t$-value $=4.461, \mathrm{p}=.001)$. In contrast, mother accepting the authority of the male consumer role (H6) has negatively explained the variance in daughters' attitudes towards marketplace activities and marketing practic- es $(-27 \%, t$-value $=-3.614, \mathrm{p}=.002)$. Finally, daughters' attitudes towards marketplace activities and marketing practices were not significantly influenced by mothers' attitude towards clothing brand preferences $(\mathrm{H} 2 \mathrm{c}) ; \beta=-18 \%, t$-value $=-2.424, \mathrm{p}=.07$ and mothers' perception of TV commercial advertisement oriented young children (H4b) does not affect $(-2 \%$, $t$-value $=-.277, \mathrm{p}=.812$ ) .

\section{Discussion}

The socialization of the child was best viewed as a series of learning experiences...If there were similarities between the developmental courses of different children, this could be attributed to similarities in the way they had been treated rather than to biologically determined stages (Zigler et al. 1982, p. 25). That is, parents' value transmission is dependent on to which extent children perception of their parents' values (Whitbeck, \& Grecas, 1988). Moreover, a scant research has examined how parents' intergenerational influence affect the consumption behaviors of family members over later stages of life within the context of collectivist cultures (Viswanathan et al., 2000). Mandrik, Fern and Bao (2005) highlight the importance of investigating the contribution of factors that influence parent-child agreement. 


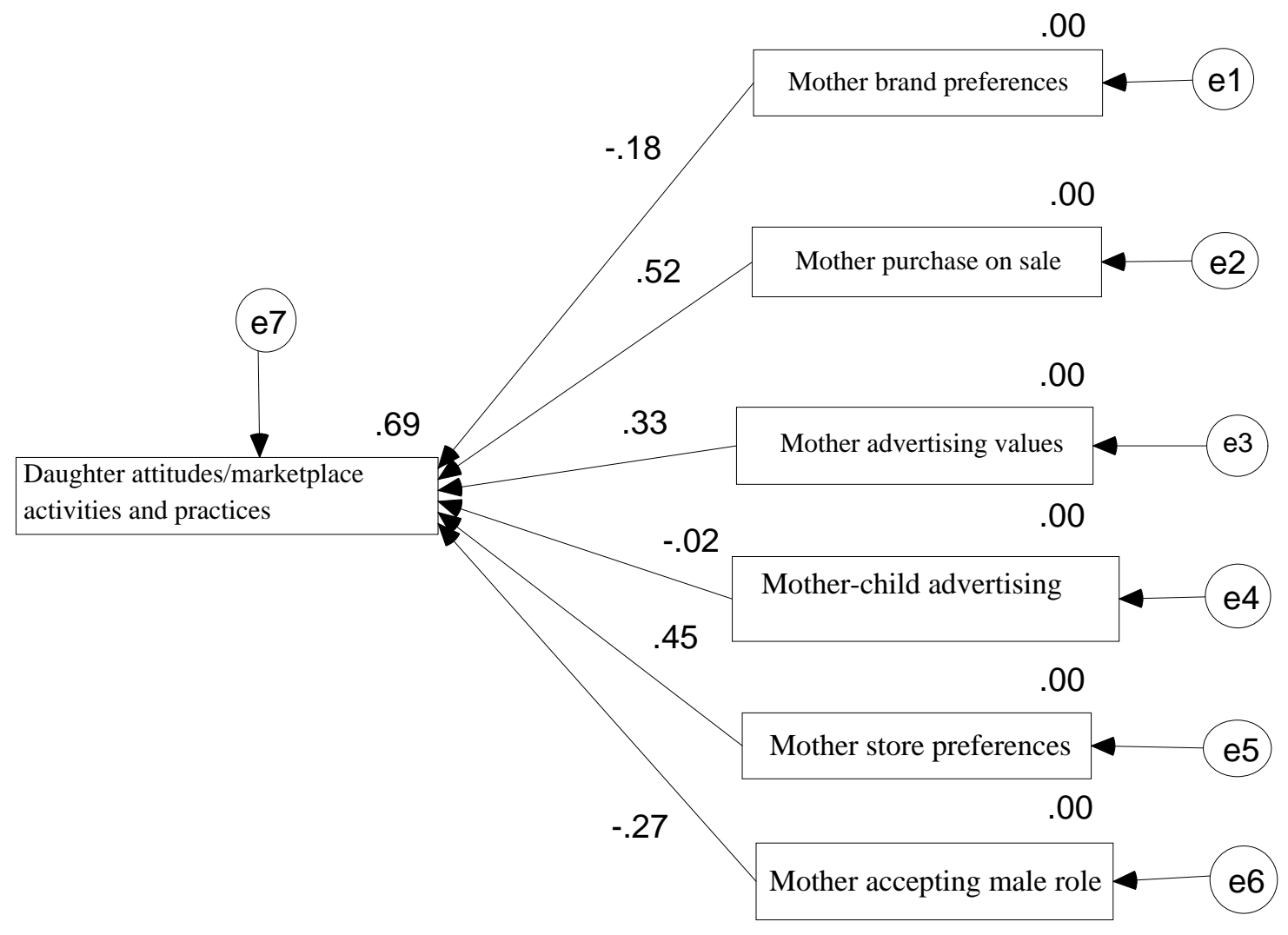

Figure 2. Model's parameter estimates

Consequently, the results revealed that mothers and young daughters did not share similar attitudes towards clothing brand preferences and TV advertising values while the similarity was found between mothers and daughters on purchasing clothing items on sale, clothing store preferences, children's commercial advertisements, and their attitudes towards accepting the authority of male consumer role. According to the relative effects, the results suggest that the general attitudes of daughters towards marketplace activities and practices are influenced by mother's attitudes towards purchasing clothing items on sale, clothing store preferences, and mothers' attitude towards TV advertising values. In general, these results are in alignment with prior research findings. In that, the family members have shared similar attitudes towards stores and brand preferences (Arndt, 1972) that particularly related to apparel products (Francis \& Burns, 1992). Parents influenced their children by 53\% (Cheliotis, 2010). Mothers and daughters displayed an agreement by (43\%) for low-visibility products and $(57 \%)$ for the high-visibility products (Moore-Shay \& Lutz, 1988). Contrasts to the research findings, parents have influenced their daughter's brand preferences by $27 \%$ (Mandrik et al., 2005). There is high and significant IGI agreement on brand preference (Perez et al., 2011). The reality of commercial advertising affects teenagers consumers socialization, consumption-related cognition, attitude, and values (Haq \& Rahman, 2015) because they relied on mass media as a source of information (Moschis, 1987). The family is considered as the major agency for cultural transmission that modifies the outcomes of learning process (Moschis, 1987, Ward, 1974). In this regard, the research results demonstrated that mothers who accepted the authority of male consumer roles would negatively influence daughters' attitudes towards marketplace activities and marketing practices. This result is consistent with Rodman' (1972) perspectives. Perez, Padgett, and Burgers (2011) have reported that the intergenerational influence is stronger in the collectivistic society since they scored the highest grades on the index of power distance (Hofstede, 1983).

\section{Conclusion and managerial implications}

Literature review indicates that a limited research has explored the influence of culture on parent-young adult intergenerational influence (e.g., Perez et al., 2011; Singh et al., 2003) and most studies report IGI on a group of products rather than a single product such as clothes. Clothes are highly conspicuous products (Childers \& Rao, 1992; Heckler et al., 
1989). Likewise, previous research has not yet explored mother-daughter intergenerational influence in Arab societies. Based on dyadic responses, this study fills these gaps by identifying the similarity/dissimilarity attitudes among Jordanian mothers and young adult daughters towards marketplace activities and marketing practices within the concept of collectivist culture and identifies the relative influences of mothers' orientations on their daughters. In conclusion, the results have not supported the null hypotheses excluding H1c (mother-daughter clothing brand preferences, H2c (the effect of mothers clothing brand preferences), H3a (mother-daughter TV advertising values, H3b (the significant impact of mothers attitudes towards children's commercial advertisements). Additionally, the unique contributions of independent variables that interpreting daughters' general attitudes towards marketplace activities and marketing practices are respectively accounted for mothers' attitude towards purchasing clothing items on sale, clothing stores preferences, and TV advertising values. With respect to the managerial implications, clothes retailers should understand the consumers groups concerning consumption patterns, product features, shopping behavior, media usage, store preferences, and evaluative criteria using by each group that in turn lead them to put forward effectual marketing strategies. The marketers should use a diversity of advertisement medium since mothers and daughters shared similar attitudes towards TV advertising values. Evidently, cultural values affect the buying patterns of consumers (Mooij \& Hofstede, 2010) thus global marketers' failure to understanding these issues within cultural variations would not able to customize their offerings and programs directed to a particular market segment.

\section{Limitations and future research}

The current study has focused on the intergenerational influence of working mothers and unmarried daughters related to buying clothes. In this respect, the intergenerational influence is differed by products categories (Arndt, 1972; Childers \& Rao, 1992; Mittal \& Royne, 2010; Siddiqui et al., 2012), and the IGI is also reduced after the daughter marriage (Heckler et al., 1989; Perez et al., 2011).) Consequently, it is worth noting that the results of the current study could not be applied or generalized to unemployment/retirement mothers and married daughters or to buying other product categories. For future research, the variables of this study could be investigated in other collectivist culture to see whether the results of this study are confirmed.

\section{References}

Arndt, J. (1972). Intrafamilial homogeneity for perceived risk and opinion leadership. Journal of Advertising $1(1), 40-47$.

Brim, Orville G., Jr. (1968).Adult Socialization, in Socialization and Society, J. Clausen, ed. Boston: Little Brown, 183-226.

Bagozzi, R., \& Yi, Y. (1988). On the evaluation of structural equation models, Journal of The Academy of Marketing Science, 16 (spring), 74-94.

Bearden, W. O., \& Etzel, M. J. (1982). Reference group influence on product and brand purchase decisions, Journal of Consumer Research, 9, (September), 183194.

Berger, P., \& Berger, B. (1979). Becoming a member of society in Peter I. Rose, editor, Socialization and the Life Cycle, New York: St. Martin's Press, 4-20.

Burgess, B., \& Drake-Bridges, E. (2010). Personal preferences of tween shoppers. Journal of Fashion Marketing and Management, 14 (4), 624-633.

Calder, B. J., Robertson, T. S., \& Rossiter, J. R. (1975). Children's consumer information processing. Сотmunication Research, 2(July), 307-316.

Chattalas, M., \& Harper, H. (2007). Navigating a hybrid cultural identity: Hispanic teenagers' fashion consumption influences. The Journal of Consumer Marketing, 24(6), 351-357.

Cheliotis, S. (2010). Chitter Chatter: what makes people talk about your brand? The Centre for Brand Analysis, Global Brand Forum, Cass Business School, City University London.

Childers, T. L., \& Rao, A. R. (1992). The influence of familial and peer-based reference groups on consumer decisions. Journal of Consumer Research, 19 (2), 198211.

Cotte, J., \& Wood, S. L. (2004). Families and innovative consumer behavior: a triadic analysis of sibling and parental influence. Journal of Consumer Research, 31(June), 78-86.

Danesi, M. (2004). Messages, Signs, and Meanings: A Basic Textbook in Semiotics and Communication, Canadian Scholars Press, Toronto, $\mathrm{ON}$

Francis, S. K., \& Burns, L. D. (1992). Effect of consumer socialization on clothing shopping attitudes, clothing acquisition, and clothing satisfaction. Clothing and Textiles Research Journal, 10(4), 35-39.

Haq, M., \& Rahman, S. (2015). Role of reality TV as a consumer-socialization agent of teenagers in a developing country. International Journal of Emerging Markets, 10(3), 598 -618.

Heckler, S., Childers, T., \& Arunachalam, R. (1989). Intergenerational influences in adult buying behaviors: an examination of moderating factors. Advances in Consumer Research, (16), 276-84.

Hair, J.F. Jr, Anderson, R., Tatham, R. and Black, W. (1998), Multivariate Data Analysis, 5th ed., PrenticeHall, Upper Saddle River, NJ. 
Hirschman, E. C., \& M. B., Holbrook. (1982). Hedonic consumption: Emerging, concepts, methods and propositions. Journal of Marketing, 46(3), 92-101.

Hofstede, G. (1983). National culture in four dimensions, International Studies of Management and Organization, 13(2), 46-74.

Holman, R. H. (1980). Clothing as communication: an empirical investigation.

Advances in Consumer Research, (7), 372-377.

Kefgen, M., \& Touchie-Specht, P. (1986). Individuality in clothing selection and personal appearance, New York, Macmillan Publishing Company.

Khraim, H. S. (2015). Segmentation of young consumers in Jordan in terms of their lifestyle: an exploratory study. American Journal of Business and Management 4(1), 27-37.

Lachance, M. J., Beaudoin, P., \& Robitaille, J. (2003). Adolescents' brand sensitivity in apparel: Influence of three socialization agents. International Journal of Consumer Studies, 27(1), 47-57.

Ladwein, R., Carton, A., \& Sevin, E. (2009). Transgenerational equity: the transmission of consumption practices between mother and daughter. Recherche et Applications en Marketing, 24(2), 1-26.

Lewis, B. R., \& Bingham, G. H. (1991). The youth market for financial services. The International Journal of Bank Marketing, 9 (2), 3-11.

Maccoby, E. E. (2007). Historical overview of socialization research and theory. In

J. E. Grusec, \& P. D. Hastings (Eds.), Handbook of socialization: Theory and research (pp. 13-41). NY: Guilford.

Maheswaran, D., \& Shavitt, S. (2000). Issues and new directions in global consumer psychology. Journal of Consumer Psychology, 9(2), 59-66.

Mandrik, C. A., Fern, E. F., \& Bao, Y. (2005). Intergenerational influence: roles of conformity to peers and communication effectiveness. Psychology \& Marketing, 22(10), 813-832.

Miller, B. C. (1975). Intergenerational patterns of consumer behaviour, Advances in Consumer Research, 2(1) 93101.

Minahan, S., \& Huddleston, P. T. (2010). Shopping with mum-mother and daughter consumer socialization. Young Consumers, 11(3), 170-177.

Mittal, B., \& Royne, M. B. (2010). Consuming as a family: modes of intergenerational influence on young adults. Journal of Consumer Behaviour, 9(4) 259-251.

De Mooij, M., \& Hofstede, G. (2010). The Hofstede model applications to global branding and advertising strategy and research. International Journal of Advertising, 29 (1) 85-110.

Moore, E. S., Wilkie, W. L., \& Lutz, R. J. (2002). Passing the torch: intergenerational influence as a source of bran equity, Journal of Marketing, 66(5), 17-37.

Moore-Shay, E.S. \& Berchmans, B.M. (1996). The role of family environment in the development of shared consumption values: an intergenerational study. Advances in Consumer Research, 23(1), 484-90.

Moore-Shay, E.S. \& Lutz, R.J. (1988). Intergenerational influences in the formation of consumer attitudes and beliefs about the marketplace: mothers and daughters. Advances in Consumer Research, 15(1), 461-67.

Moschis, G. P. (2007). Life course perspectives on consumer behaviour. Journal of the Academy of Marketing Science, 35(2), 295-307.

Moschis, G, P. (1987). Consumer Socialization: A Life Cycle Perspective, Boston: Lexington Books.

Moschis, G. P. (1988). Methodological issues in studying intergenerational influences on consumer behavior. In M.J. Houston (Ed.), Advances in consumer research, 15(1), $569-573$.

Neeley, S. (2005). Influences on consumer socialization. Young Consumers, 6(2), 63-9.

Newcomb, T. (1953).An approach to the study of communicative acts. Psychological Review, 60(November), 393-404.

Obermiller, C., \& Spangenburg, E. R. (2000). On the origin and distinctiveness of skepticism toward advertising, Marketing Letters, 11 (4), 311-22.

Opoku, R. (2012). Young Saudi adults and peer group purchase influence: a preliminary investigation. Young Consumers, 13(2), 176-187.

Perez, M. E., Padgett, D., \& Burgers, W. (2011). Intergenerational influence on brand preferences. Journal of Product \& Brand Management, 20(1), 5-13

Roberts, M., Wortzel, L., \& Berkeley, R. (1981). Mothers' attitudes and perceptions of children's influence and their effect on family consumption. Advances in Consumer Research, 8(1), 730-735.

Rodman, H. (1972). marital power and the theory of resources in cross-cultural context. Journal of Comparative Family Studies. 3(1), 50-69.

Shah, R. H., \& Mittal, B. (1997). Toward a theory of intergenerational influence in consumer behavior: an exploratory essay, Advances in Consumer Research, 24(1), 55-60.

Shobri, N., M., Ahmad, S., Naqsa, N. (2012). The Influence of consumer socialization on brand loyalty: survey on Malaysian fast food consumer, Procedia-Social and Behavioral Sciences (65), 523-529.

Shoup, J., A. (2007). In Culture and customs of the Middle East, 1550-1310. Greenwood Press. 2007.

Siddiqui, K., Bashir, S., Sarki, I., \& Abbas, S. (2012). Intergenerational Influences on brand preferences: consumables vs durables, International Journal of Business and Social Science, 3(13), 227-231.

Singh, N., Kwon, I-W., \& Pereira, A. (2003). Crosscultural consumer socialization; an exploratory study of socialization influences across three ethnic groups. Psychology \& Marketing, 20(10), 867-81.

Steiger, J., H. (1990). Structural model evaluation and modification: an interval estimation approach, Multivariate Behavioral Research, 25(April), 173-80.

Triandis, H. C. (1995). Individualism and collectivism. Boulder, CO: Westview Press.

Triandis, H. C., \& Gelfand, M. (1998). Converging measurement of horizontal and vertical individualism and collectivism. Journal of Personality and Social Psychology, 74(1), 118-28.

Viswanathan, M., Childers, T. \& Moore E. (2000). The measurement of intergenerational communication and influence on consumption: development, validation, 
and cross-cultural comparison of the IGEN scale. Journal of the Academy of Marketing Science, 28(3), 406-424.

Ward, S., Kless, D. M., \& Robertson, T. S. (1987). Consumer socialisation in different settings: an International perspective. Advances in Consumer Research, 14(1), 468-472.

Ward, S. (1974). Consumer socialization. Journal of Consumer Research, 1(Sept),1-14.

Watne, T., Lobo, A., \& Brennan, L. (2011). Children as secondary socialisation agents for their parents. Young Consumers, 12(4), 285-294.

Webster, Cynthia, \& Wright, L., B. (1999). The effects of strength of family relationship on intergenerational influence. Advances in Consumer Research, 26(1),373378.
Whitbeck, L, B., \&, Gecas. V. (1988). Value Attributions and Value Transmission between Parents and Children, Journal of Marriage and the Family, 50(August), 829-840.

Wilkie, W. (1986). Consumer Behaviour. New York: Wiley \&. Sons.

Yamaguchi, S., Kuhlman, D. M., \& Sugimori, S. (1995). Personality correlates of allocentric tendencies in individualist and collectivist cultures. Journal of CrossCultural Psychology, 26(6) 658-72.

Yates, G. C., \& Cutler, B. D. (1996). Hofstede's Model of National Culture. Journal of Teaching in International Business, 8(2), 77-93.

Zigler, E., Lamb, M. and Child, I. (1982). Socialization and personality development, $2^{\text {nd }}$ edit., New York: Oxford University Press. 